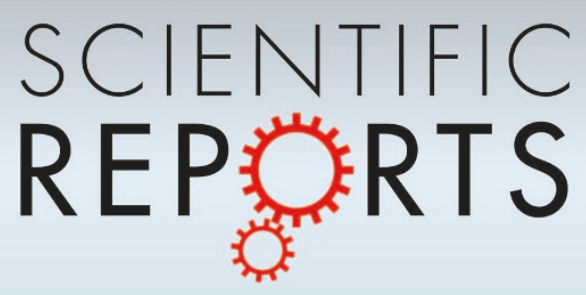

OPEN

SUBJECT AREAS:

ORGANIC LEDS

OPTOELECTRONIC DEVICES AND COMPONENTS

Received

30 April 2014

Accepted

3 October 2014

Published

24 October 2014

Correspondence and requests for materials should be addressed to

W.F.X. (xiewf@jlu. edu.cn)

\section{Efficient non-doped phosphorescent orange, blue and white organic light-emitting devices}

\author{
Yongming Yin' , Jing Yu' ', Hongtao $\mathrm{Cao}^{2}$, Letian Zhang' ${ }^{1}$, Haizhu Sun² \& Wenfa Xie'
}

\begin{abstract}
'State Key Laboratory on Integrated Optoelectronics, College of Electronic Science and Engineering, Jilin University, 2699 Qianjin Street, Changchun, 130012, China, ${ }^{2}$ College of Chemistry, Northeast Normal University, Changchun, Jilin, 130024, P. R. China.
\end{abstract}

Efficient phosphorescent orange, blue and white organic light-emitting devices (OLEDs) with non-doped emissive layers were successfully fabricated. Conventional blue phosphorescent emitters bis

[4,6-di-fluorophenyl]-pyridinato-N, $\left.\mathrm{C}^{\prime}\right]$ picolinate (Firpic) and Bis(2,4-difluorophenylpyridinato) (Fir6) were adopted to fabricate non-doped blue OLEDs, which exhibited maximum current efficiency of 7.6 and $4.6 \mathrm{~cd} / \mathrm{A}$ for Firpic and Fir6 based devices, respectively. Non-doped orange OLED was fabricated utilizing the newly reported phosphorescent material iridium (III) (pbi) ${ }_{2} \operatorname{Ir}(\mathrm{biq})$, of which manifested maximum current and power efficiency of $8.2 \mathrm{~cd} / \mathrm{A}$ and $7.8 \mathrm{~lm} / \mathrm{W}$. The non-doped white OLEDs were achieved by simply combining Firpic or Fir6 with a $2-\mathrm{nm}(\mathrm{pbi})_{2} \operatorname{Ir}(\mathrm{biq})$. The maximum current and power efficiency of the Firpic and $(\mathrm{pbi})_{2} \operatorname{Ir}(\mathrm{biq})$ based white OLED were $14.8 \mathrm{~cd} / \mathrm{A}$ and $17.9 \mathrm{~lm} / \mathrm{W}$.

\footnotetext{
$\mathrm{R}$
} ecently, products based on organic light-emitting device (OLED) technology have come into our daily life in the past two years. But the price of such kind of products is still very high and unaffordable to most of the consumers. So it's desperately demanded to fabricate excellent performance devices with simple structures and then reduce fabrication complexity, thus to lower the prices and promote the commercialization of OLED products.

At present, simple structure devices can be mainly divided into three categories: i) single-layer devices ${ }^{1-5}$, which only exhibit one emission layer (EML), between two electrodes, that also shoulders the functions of transporting charge carriers; ii) homojunction devices ${ }^{6-9}$, which are fabricated with only one sort of bipolar matrix material through electrical and photonic doping; iii) non-doped devices ${ }^{10-17}$, which are free of any kinds of doping through all the function layers. The power efficiency of one single-layer white OLED based on a bipolar host 2,7-bis (diphenylphosphoryl)-9-[4-(N,N-dipheny-lamino) phenyl]-9-phenylfluorene (POAPF) could reach $20.9 \mathrm{~lm} / \mathrm{W}$ @ $1000 \mathrm{~cd} / \mathrm{m}^{2}$, which also could reach $14.5 \mathrm{~lm} / \mathrm{W}$ at a very high brightness of $5000 \mathrm{~cd} / \mathrm{m}^{23}$. Cai et al. demonstrated efficient red, green and blue phosphorescent $\mathrm{p}$-i-n homojunction devices adopting three similar bipolar host materials (2,6-bis(3-(carbazol-9-yl)phenyl) pyridine, 3,5-bis(3-(carbazol-9-yl)phenyl) pyridine and 4,6bis(3-(carbazol-9-yl)phenyl) pyrimidine) $)^{7}$. As to non-doped monochromatic devices, Liu et. al. enhanced efficiency and reduced efficiency-roll-off by adopting quantum well structures ${ }^{10,11}$. Liu and coworkers developed a series of excellent green phosphorescent materials which exhibit superior electron/hole transporting property for non-doped OLEDs ${ }^{12-14}$, which still hold the efficiency records of $70 \mathrm{~lm} / \mathrm{W}$ to phosphorescent OLEDs based on a neat EML. Excellent red non-doped OLEDs have also been reported ${ }^{15,16}$. In 2013, Xia et. al. developed a blueemitting iridium dendrimer with carbazole dendrons for solution-processed non-doped phosphorescent OLEDs, which gave a state-of-art external quantum efficiency (EQE) as high as $15.3 \%(31.3 \mathrm{~cd} / \mathrm{A}, 28.9 \mathrm{~lm} / \mathrm{W})$ along with CIE coordinates of $(0.16,0.29)^{17}$. But high-performance non-doped orange OLEDs free of ultrathin $(<1 \mathrm{~nm})$ layers are rather scarce, of which could be utilized to combine with sky-blue dyes to enable white-light emission. In addition, traditional blue phosphorescent dyes iridium (III) bis[4,6-di-fluorophenyl]-pyridinato-N, $\left.\mathrm{C}^{2}\right]$ picolinate (Firpic) and Bis(2,4-difluorophenylpyridinato) (Fir6) were merely adopted in host-guest system and there is no reports about the non-doped devices with Firpic or Fir6. For the non-doped white devices, there are only some results achieved through emission from electromers ${ }^{18}$, exciplexes ${ }^{19}$ or ultrathin $(\sim 0.1 \mathrm{~nm})$ layers of phosphorescent dyes with state-of-art maximum current and power efficiency of $41.3 \mathrm{~cd} / \mathrm{A}$ and $44 \mathrm{~lm} / \mathrm{W}^{20,21}$, or all fluorescent materials ${ }^{22,23}$. Above all, it's meaningful and demanded to develop excellent non-doped orange and white OLEDs which are free of ultrathin layers of neat phosphorescent dyes. 


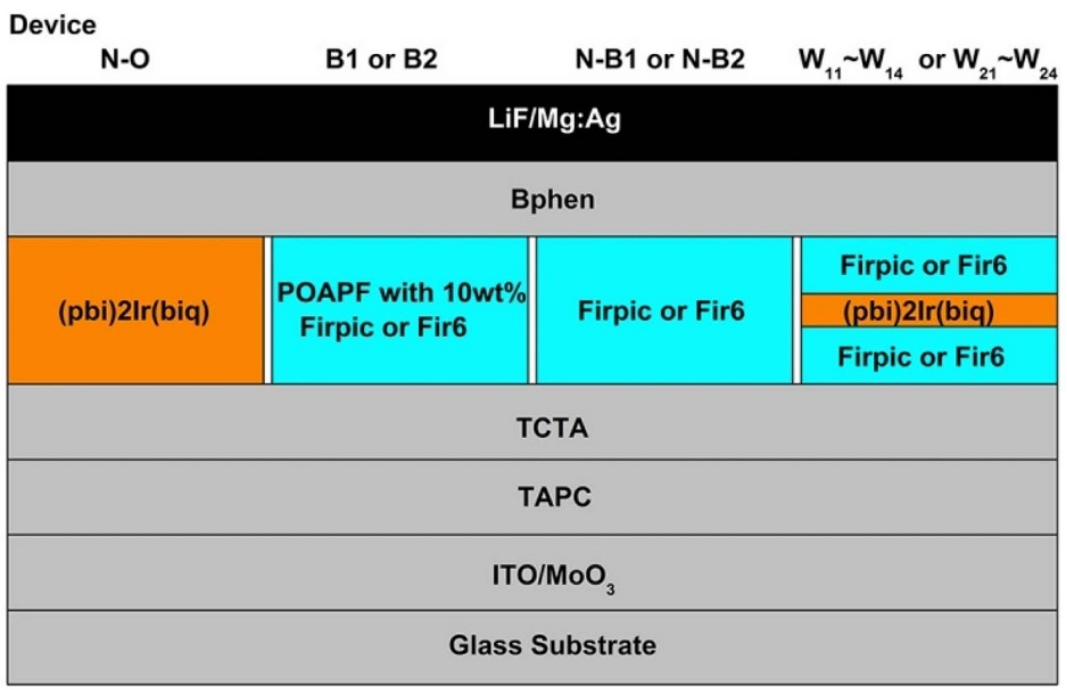

Figure $1 \mid$ Device structures of the orange, blue and white OLEDs.
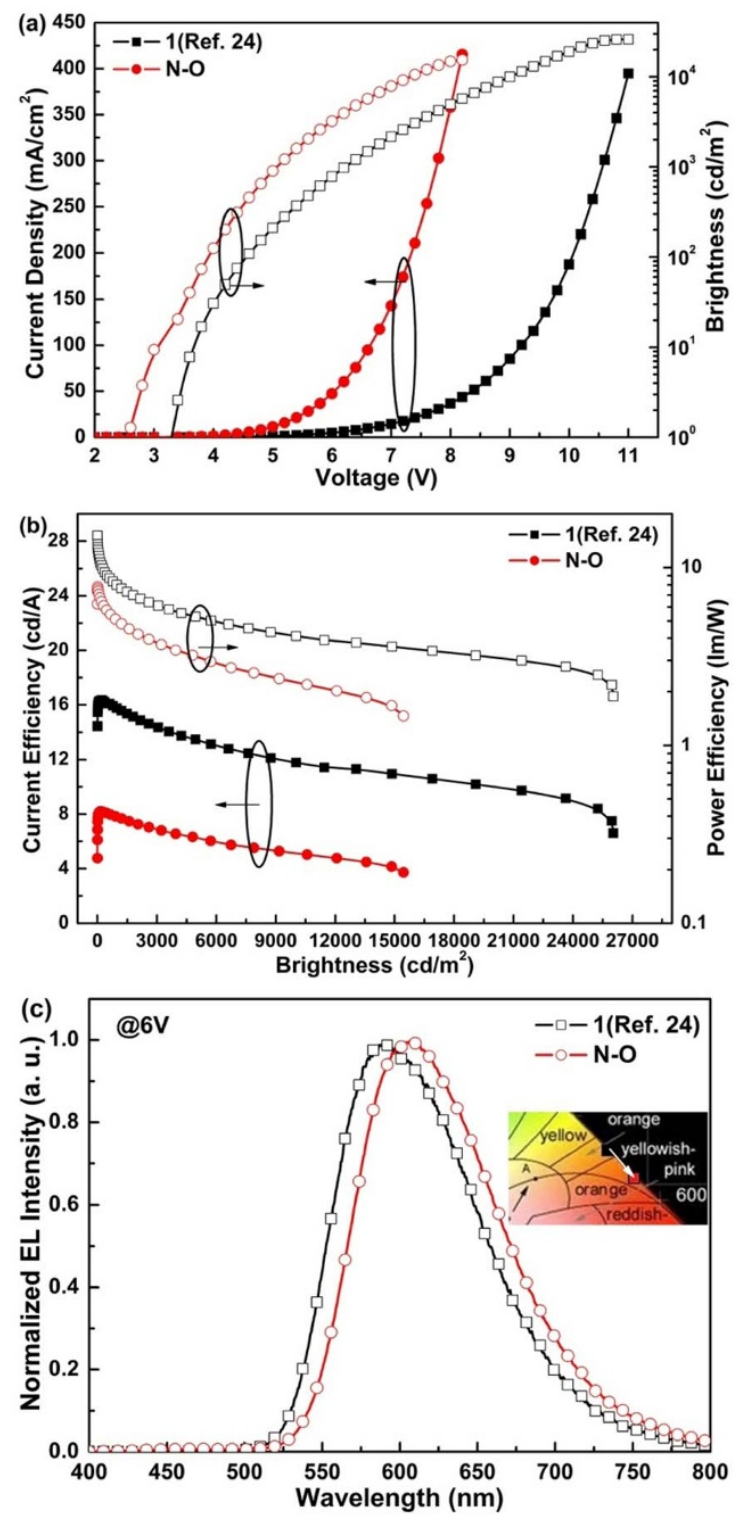

Figure $2 \mid$ (a) The current density-voltage-brightness, (b) current efficiency-brightness-power efficiency and (c) EL spectra characteristics of devices N-O and 1(ref. 24).
In this paper, efficient phosphorescent orange, blue and white OLEDs were successfully fabricated adopting a wide-bandwidth orange phosphorescent material iridium (III) (pbi) $2 \operatorname{Ir}(\mathrm{biq})^{24}$, and widely-used blue dyes Firpic and Fir6. The monochrome and white OLEDs share the similar device structure and exhibit high efficiency, all of which were rather scarce as non-doped ones free of ultrathin layers by thermal vacuum evaporation technique as to the best of our knowledge.

Firstly, a non-doped orange OLED (marked as N-O device) with device structure as following was fabricated: ITO/ $\mathrm{MoO}_{3}(3 \mathrm{~nm}) / 1,1$ Bis [(di-4-toly-lamino)phenyl $]$ cyclohexane (TAPC) $(35 \mathrm{~nm}) / 4,4^{\prime}, 4^{\prime \prime}$ tris(Ncarbazolyl)triphenylamine (TCTA) $\quad(5 \mathrm{~nm}) /(\mathrm{pbi})_{2} \operatorname{Ir}(\mathrm{biq})$ (20 nm)/4,7-Diphenyl-1,10-phenanthroline (Bphen) $(40 \mathrm{~nm}) / \mathrm{LiF}$ $(0.5 \mathrm{~nm}) / \mathrm{Mg}: \mathrm{Ag}$ (15:1 by weight, $120 \mathrm{~nm})$, which was generally depicted in Fig. 1, which also denoted the general device structure of other OLEDs mentioned in this paper after.

The characteristics of $\mathrm{N}-\mathrm{O}$ device were showed in Fig. 2. Maximum current and power efficiency $\left(\eta_{\mathrm{c}}, \eta_{\mathrm{p}}\right)$ of $8.2 \mathrm{~cd} / \mathrm{A}$ and $7.8 \mathrm{~lm} / \mathrm{W}$ were obtained as indicated in Fig. 2 (b) and summarized in Table 1. Such excellent performance could be attributed to two possible factors: i) excellent charge transport properties of (pbi) $)_{2} \operatorname{Ir}(\mathrm{biq})$, which could be concluded for the relative higher current density under same bias than that of device 1 (ref. 24); ii) aggregation induced quenching is not serious, given the quantum yield $(\sim 0.22)$ of neat (pbi) $)_{2} \operatorname{Ir}(\mathrm{biq})$ film by thermally evaporated is not too low. But the efficiency of $\mathrm{N}-\mathrm{O}$ device was still a little lower than that of device 1 (ref. 24), which could mainly due to the aggregation induced quenching and red-shifts in EL spectrum of N-O device. Fig. 2 (c) depicted the EL spectra of N-O device and device 1(ref. 24), of which manifested obvious red-shifts of $14 \mathrm{~nm}$ from device 1 (ref. 24) to N-O device. This phenomenon was arisen from the aggregate species, of which is similar as indicated in the photoluminescence (PL) spectra of our former works ${ }^{24}$. In addition, no extra emission was found in the EL spectrum of N-O device, so most of the excitons could be well confined in the EML and then recombined in (pbi) $)_{2} \operatorname{Ir}(\mathrm{biq})$ to enable orange emission.

The excellent performances combining with properties of widebandwidth of N-O device evoked us to use (pbi) ${ }_{2} \operatorname{Ir}(\mathrm{biq})$ in nondoped white OLEDs by combine with another sky-blue dyes, since we have already achieved efficient two-waveband white OLED with high CRI of 80 via adopting Fir6 as complementary dye for white emission $^{24}$. In advance of fabricating white-emission OLEDs, nondoped blue ones marked as N-B1 and N-B2 devices were fabricated utilizing conventional blue phosphorescent dyes Firpic and Fir6 which were merely adopted in host-guest systems by researchers 


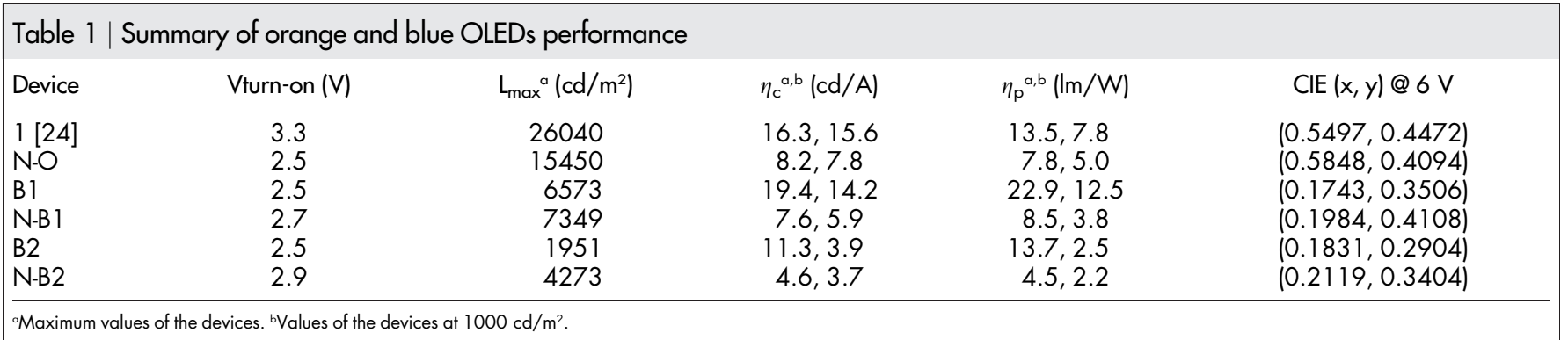

since reported. For comparison, traditional blue OLEDs by doping 10 wt\% Firpic or Fir6 into 2, 7-bis (diphenylphosphoryl)-9-[4(N,Ndiphenylamino)phenyl]-9-phenylfluorene (POAPF) were also fabricated with same other function layers as $\mathrm{N}-\mathrm{O}$ device, of which were marked as device B1 and B2. The device structures were also depicted in Fig. 1.

Fig. 3 depicted the device EL properties of these four blue OLEDs. Seen from Fig. 3 (a), lower turn-on (bias at a brightness of $1 \mathrm{~cd} / \mathrm{m}^{2}$,
$\mathrm{V}_{\text {turn-on }}$ ) and driving voltages were found in device $\mathrm{B} 1$ and $\mathrm{B} 2$ than those of corresponding N-B1 and N-B2 devices, which could be attributed to the more excellent bipolar transport characteristics of $\mathrm{POAPF}^{25}$ than that of Firpic ${ }^{26}$. However, the current density-voltage characteristics of these four devices were almost identical. It is possibly because of Firpic could somewhat transport charges ${ }^{26}$ and the doping of Firpic in POAPF also helped to enhance electron injection or transport ${ }^{5}$. In addition, maximum current efficiencies of 7.6 and
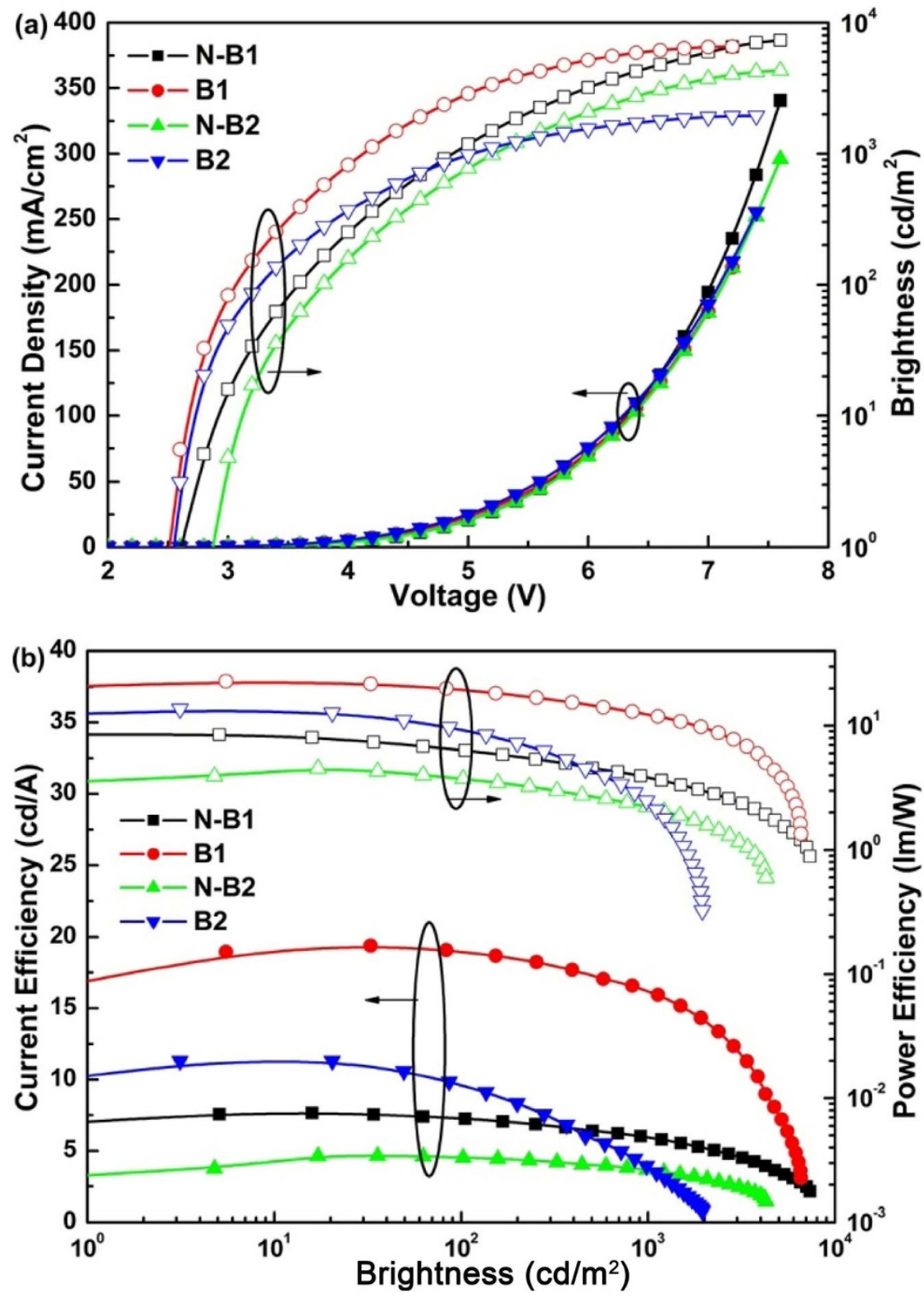

Figure 3 | (a) The current density-voltage-brightness, and (b) current efficiency-brightness-power efficiency of blue OLEDs. 

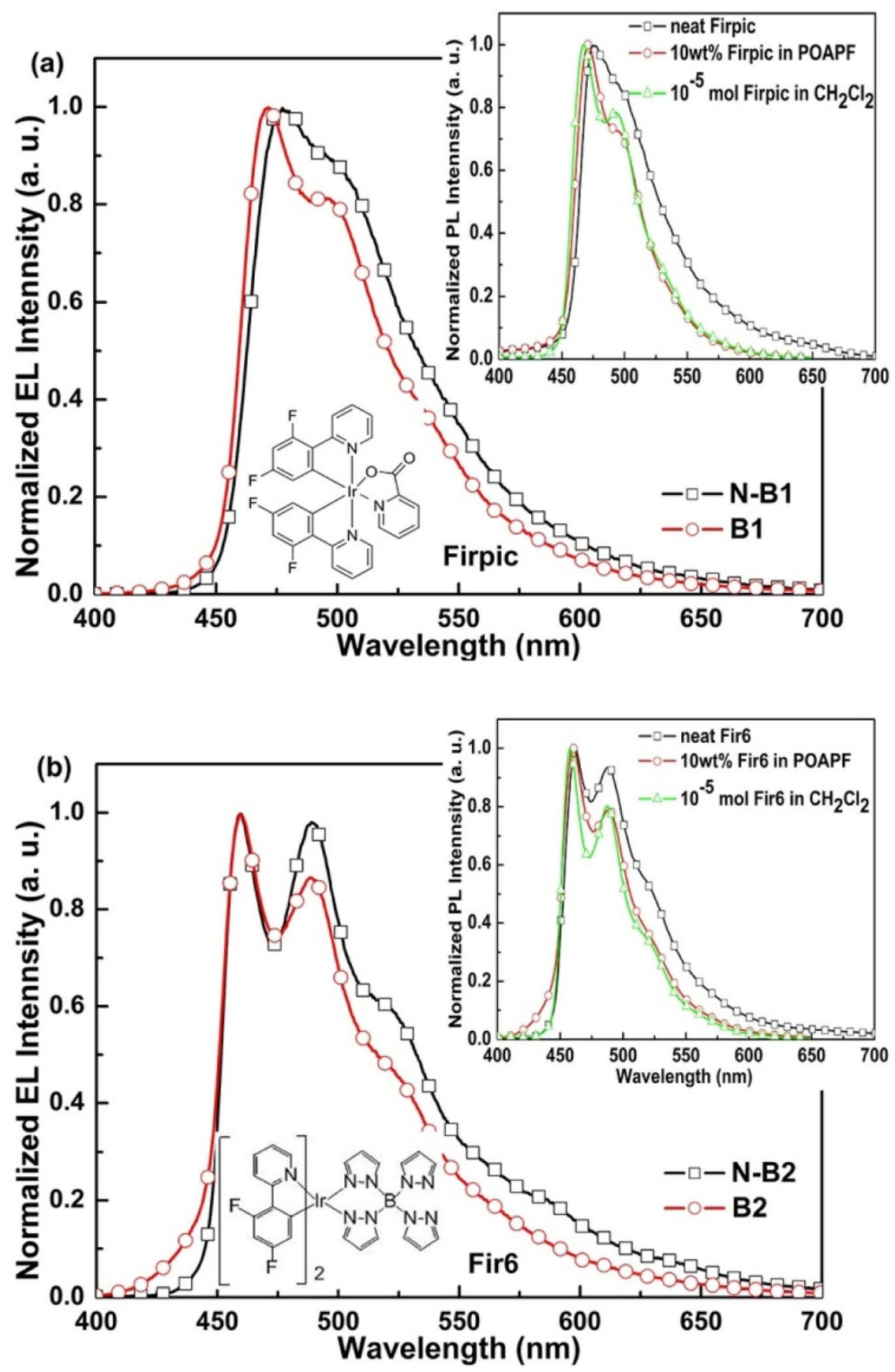

Figure $4 \mid$ The EL spectra of blue OLEDs. The insets were corresponding PL spectra.

$4.6 \mathrm{~cd} / \mathrm{A}$ were achieved by N-B1 and N-B2 devices, although not comparable to and approximately half of those of corresponding traditional devices B1 and B2. It was possibly due to following two factors: i) Limited charge transport properties of Firpic and Fir6, of which pave the way for the transport of charges and thus form quantities of excitons to enable light emission ${ }^{12-14}$; ii) the non-planar molecular structure of the two blue emitters because of the two adjacent fluorophenylpyridinato substituents (see structures depicted in insets of Fig. 4), of which led their molecules to have amorphous nature in solid state and have a weak interaction between molecules and thus with weak or no concentration-quenching effect as non-doping material ${ }^{27-30}$. iii) the photoluminescence quantum efficiency (PLQE) of neat Firpic and Fir6 films were 0.15 and 0.11 respectively.

The EL spectra of the four devices were depicted in Fig. 4, with corresponding photoluminescence (PL) spectra inset on the right corner and molecular structure inset below the EL spectra. Weak emission at $\sim 425 \mathrm{~nm}$ in the spectra of device B2 was possibly arisen from the host emission because of deficient energy transfer from host to guest. Both N-B1 and N-B2 devices denoted stronger shoulder emission compared to corresponding doped devices. It maybe attributed to the different strength of the vibrational emission band. The main band is from $0-0$ transition, the first shoulder from $0-1$ transition and the second shoulder from 0-2 transition of T1, and so on ${ }^{31}$. The vibrational emission band would become stronger along with the shorting of the wavelength of the main band ${ }^{32}$. This is in accordance with the case of Firpic and Fir6 as indicated in Fig. 4. The doping concentration of the emitters will influence the strength of the vibrational emission band and so does the shoulder emission. Here, we thought the strength of the vibrational emission band was stronger in neat films compared to that in 10wt\% doped POAPF. In 2003, Holmes et. al. have already reported similar phenomenon ${ }^{33}$. On the 
Firpic

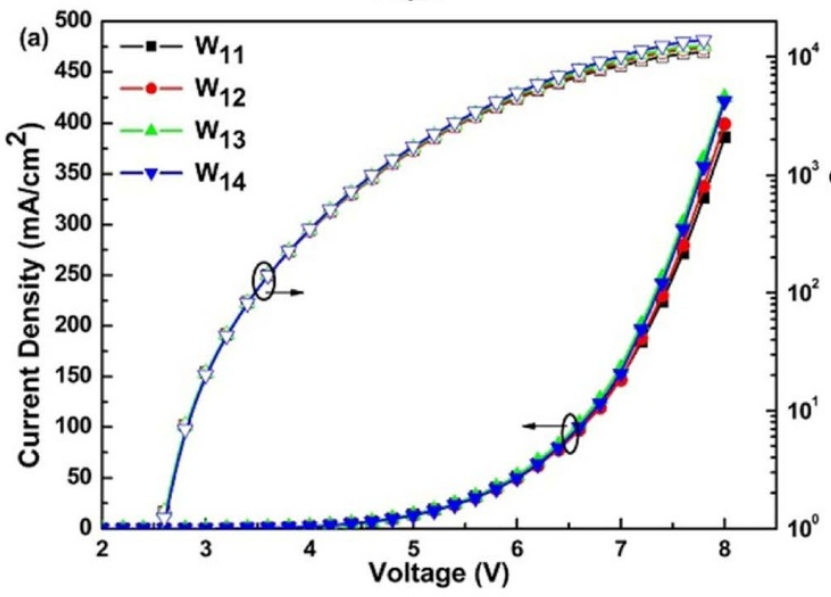

Firpic

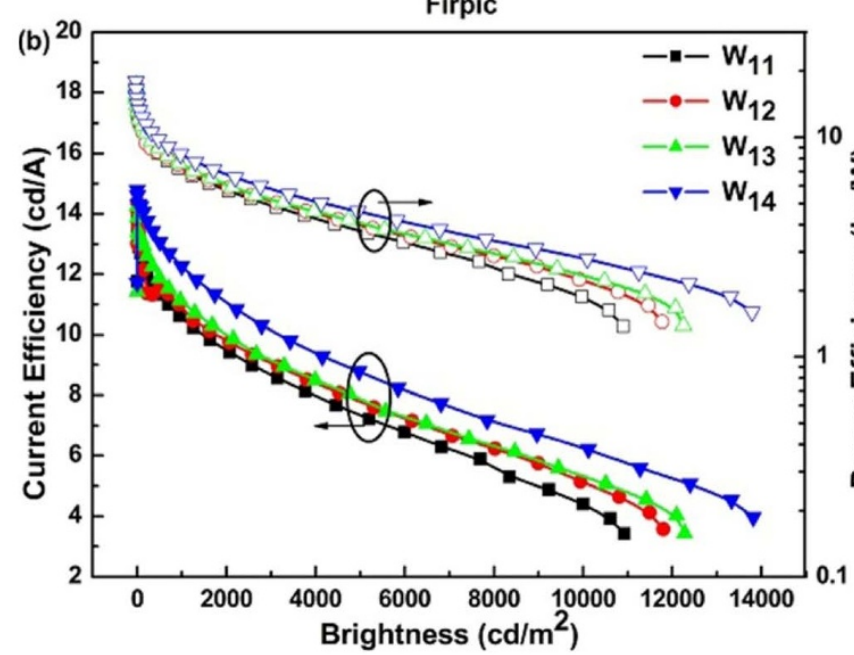

Fir6

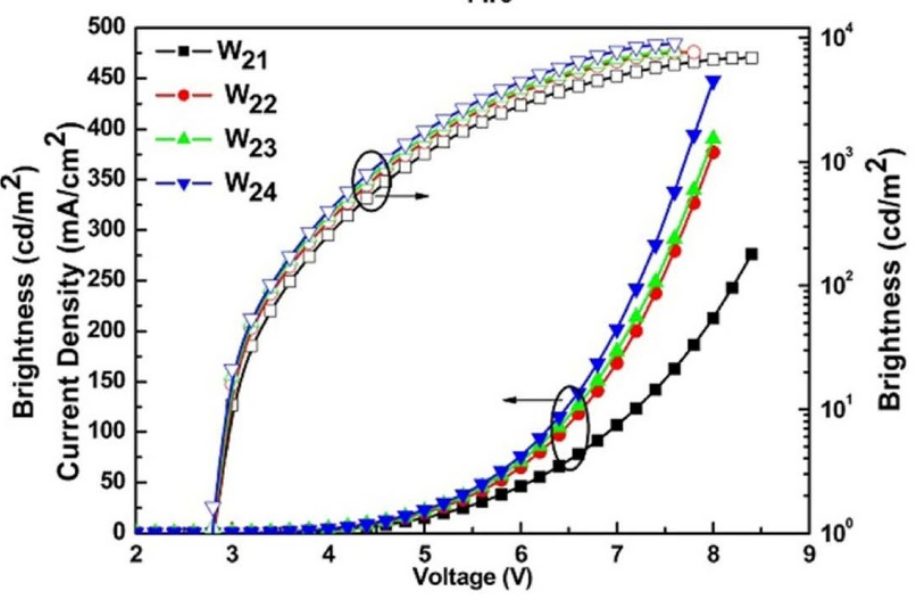

Fir6

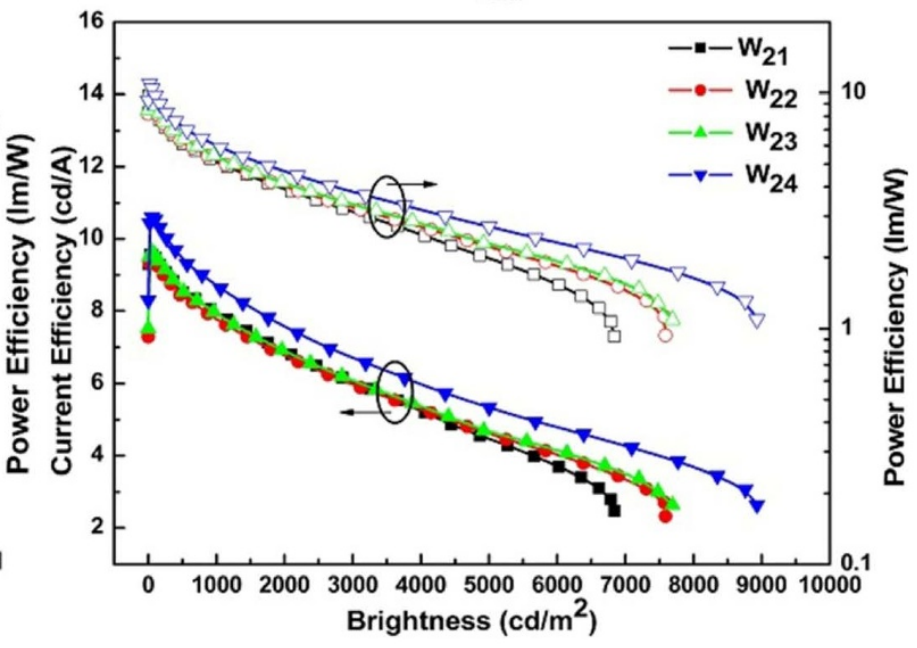

Figure $5 \mid$ (a) The current density-voltage-brightness, and (b) current efficiency-brightness-power efficiency of white OLEDs.

other hand, weak microcavity effect ${ }^{34}$ would also have an influence on the changes in the strength of the shoulders. The non-doping of the EML would change the exciton recombination zone because of the different transport properties between emitters and POAPF. The PL spectra were in accord with the corresponding EL spectra.

Based on above results, two series of white OLEDs (WOLEDs) were successfully fabricated by simply stacking the orange and blue neat films in the EML. The device structures of one series were as following: ITO/ $\mathrm{MoO}_{3}(3 \mathrm{~nm}) / \mathrm{TAPC}(35 \mathrm{~nm}) / \mathrm{TCTA}(5 \mathrm{~nm}) /$ Firpic $[(20-\mathrm{x}) \mathrm{nm}] /(\mathrm{pbi})_{2} \operatorname{Ir}(\mathrm{biq})(2 \mathrm{~nm}) /$ Firpic $(\mathrm{x} \mathrm{nm}) /$ Bphen $(40 \mathrm{~nm}) /$ $\mathrm{LiF}(0.5 \mathrm{~nm}) / \mathrm{Mg}: \mathrm{Ag}$ (15:1 by weight, $120 \mathrm{~nm}), \mathrm{x}=0,3,5$ and 10 respectively corresponding to devices W11 to W14. Devices W21 to W24 were achieved by simply replacing Firpic with Fir6. The device structures were also depicted in Fig. 1. The device EL properties of these two series WOLEDs were shown in Fig. 5 and summarized in Table 2. Fig. 5 (a) showed their current density-voltage-brightness (JV-L) characteristics of the WOLEDs. As can be seen, the current density deceased as the (pbi) ${ }_{2} \operatorname{Ir}$ (biq) film shifted from the cathode side to the anode side, which could be attributed to the trap of charges by (pbi) $)_{2} \operatorname{Ir}($ biq). On the contrary, the device brightness increased. We attrubited it to the electron-dominant transporting characteristics of Firpic and Fir6, which led to excitons mainly concentrate in the region close to the anode. As the movement of (pbi) $)_{2} \operatorname{Ir}(\mathrm{biq})$ and approaching to the main exciton recombination zone, the orange emission became stronger and thus result in higher device efficiency as indicated in Fig. 5 (b). The increase of device efficiency was

\begin{tabular}{|c|c|c|c|c|c|}
\hline W11 & 2.4 & 10920 & $14,10.5$ & $16.9,7.2$ & $(0.3320,0.4234),-$ \\
\hline W13 & 2.4 & 12280 & $14.4,11$ & $17.4,7.6$ & $(0.3921,0.4139)^{\prime},-$ \\
\hline W14 & 2.4 & 13820 & $14.8,12.2$ & $17.9,8.4$ & $(0.4750,0.4192), 76$ \\
\hline W21 & 2.8 & 6839 & $9.5,7.9$ & $9.7,5.1$ & $(0.2719,0.3510),-$ \\
\hline W24 & 2.8 & 8933 & $10.6,8.7$ & $10.9,6$ & $(0.4020,0.3862), 80$ \\
\hline
\end{tabular}




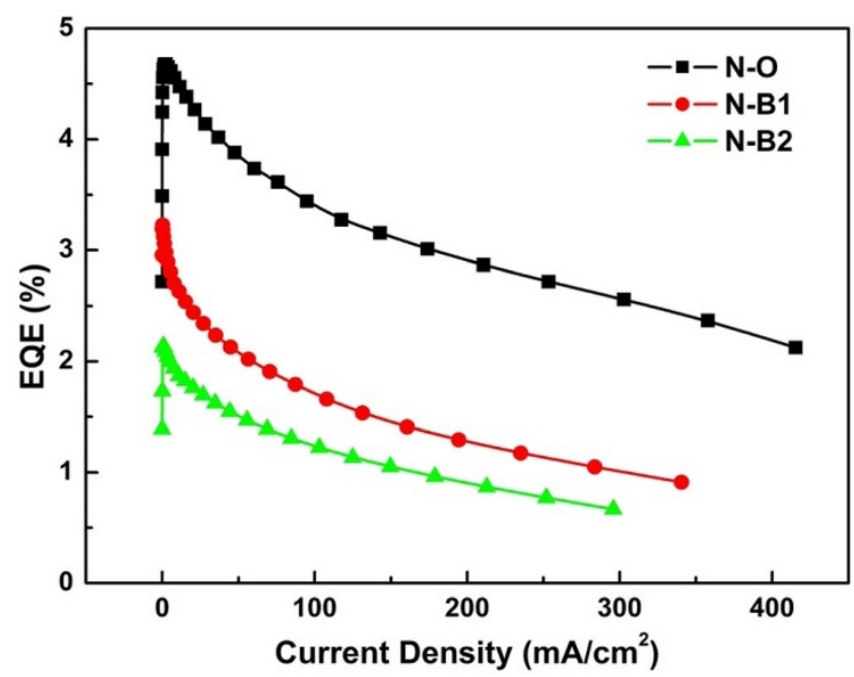

Figure 6 | EQE-current density characteristics of non-doped orange and blue OLEDs.

due to the relative higher external quantum efficiency (EQE) of (pbi)2Ir(biq) based non-doped monochrome device (i. e. N-O) than those of Firpic and Fir6 based ones (i. e. N-B1 and N-B2) under same bias as manifested in Fig. 6. Maximum current efficiency and power efficiency of $14.8 \mathrm{~cd} / \mathrm{A}$ and $17.9 \mathrm{~lm} / \mathrm{W}$ were achieved in device W14, of which were rare to non-doped two-color WOLED. The detailed EL properties of the WOLEDs were summarized in Table 2.
Fig. 7 depicted the EL spectra of the WOLEDs. Fig. 7 (a) showed the EL spectra of the WOLEDs at $6 \mathrm{~V}$. As can be seen, the emission from (pbi) ${ }_{2} \operatorname{Ir}(\mathrm{biq})$ became stronger as the (pbi) $)_{2} \operatorname{Ir}(\mathrm{biq})$ layer shifted from cathode side to anode side and thus the device CIE coordinates moved to the warm white and reached to the Planckian locus as indicated on the inset figure, of which was in accord with above discussion. Fig. 7 (b) denoted the EL spectra of W14 and W24 under different driving voltage. The CIE coordinates of both W14 and W24 were closed to the Planckian locus under different bias. In a tolerable Duv, the CRI of W14 could be as high as 78 and that of W24 could reach even higher to 80 , which was scarce for two-element white OLEDs.

\section{Conclusions}

In conclusion, efficient orange, blue and white phosphorescent nondoped OLEDs were demonstrated. Maximum current efficiency of 7.6 and $8.2 \mathrm{~cd} / \mathrm{A}$ were achieved respectively by monochrome blue and orange non-doped ones. The non-doped WOLED not only exhibited high maximum current and power efficiency of $14.8 \mathrm{~cd} /$ $\mathrm{A}$ and $17.9 \mathrm{~lm} / \mathrm{W}$ and simultaneously high $\mathrm{R}_{\mathrm{a}}$ of 78 with CIE coordinated closed to the Planckian locus under different driving voltage. This work will greatly reduce the complexity of the OLED fabrication process and improve the repeatability of OLEDs.

\section{Methods}

Device fabrication. The organic materials used in our experiments are purchased from Luminescence Technology Corporation. In advance of thermal vapor deposition process, the ITO glasses were cleaned using Decon 90 cleaning liquid (5\% Decon 90 in DI water) and DI water. And then, they were ultrasonically cleaned in DI water for three times with each for five minutes. After that, the ITO surface was
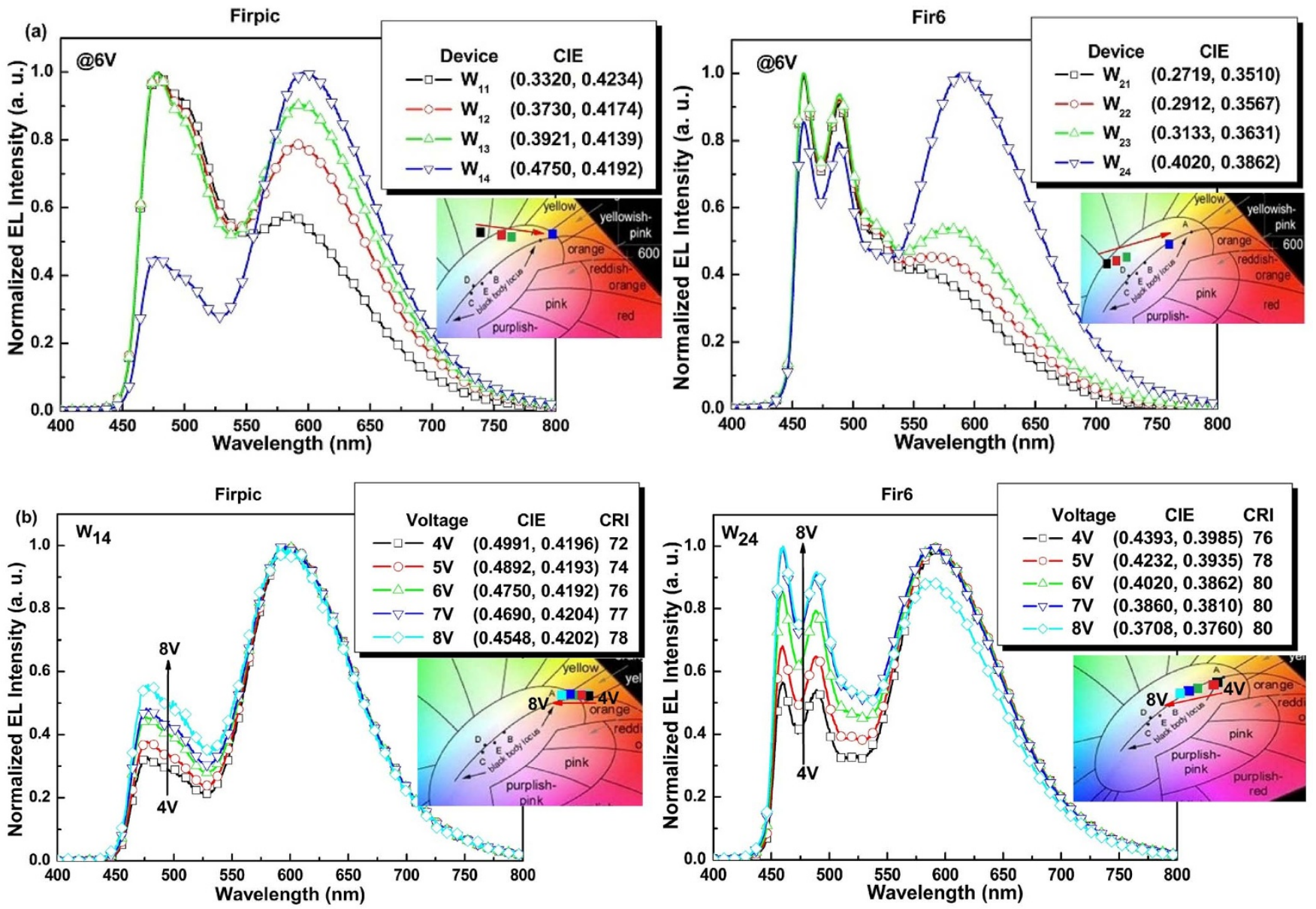

Figure $7 \mid$ (a) EL spectra of W11-W14 and W21-W24 under 6 V and (b) EL spectra of W14 and W24 under different bias. 
treated in plasma cleaner (Harrick plasma cleaner PDC-32G-2) for 10 minutes. In order to thermally evaporate the organic and metal layers on the ITO surface, we set the substrates in a vacuum evaporator, which was evacuated using a rotary mechanical pump and a turbo molecular pump. Under a background pressure of $\sim 5$ $\times 10^{-4} \mathrm{~Pa}$, organic layers and cathode materials were sequentially deposited on the substrates without breaking vacuum. A shadow mask was used to define the cathode and to make four $10 \mathrm{~mm}^{2}$ devices on each substrate. The organic layers were thermally deposited at a general rate of $\left.\sim 1 \AA / s(\sim 0.2 \AA / s \text { to that of (pbi) })_{2} \operatorname{Ir}(\mathrm{biq})\right)$ in a vacuum monitored in situ with the quartz oscillator. The cathode was completed through thermal deposition of $\operatorname{LiF}(5 \AA)$ at a deposition rate of nearly $0.1 \AA / s$ and then capping with $\mathrm{Mg}$ : Ag metal (150 nm, 15:1 by weight). The doped layers were achieved by simultaneously evaporating the guest and host material with different deposition rates monitored in situ with the quartz oscillator.

Device characterization. Luminance-current-voltage characteristics of unpackaged devices were measured simultaneously with a programmable Keithley 2400 Source Meter and a Minolta Luminance Meter LS-110 in air at room temperature. The spectra of the device were measured with Ocean Optics Maya 2000-PRO spectrometer. Emission spectra of Firpic and Fir6 under different state were recorded on a Cary Eclipse spectrofluorometer (Varian) equipped with a xenon lamp and quartz carrier at room temperature.

1. Hou, L. et al. Efficient solution-processed small-molecule single emitting layer electrophosphorescent white light-emitting diodes. Org. Electron. 11, 1344-1350 (2010).

2. Zou, J. et al. Simultaneous optimization of charge-carrier balance and luminous efficacy in highly efficient white polymer light-emitting devices. Adv. Mater. 23, 2976-2980 (2011)

3. Yin, Y. et al. High-efficiency and low-efficiency-roll-off single-layer white organic light-emitting devices with a bipolar transport host. Appl. Phys. Lett. 101, 063306-063310 (2012).

4. Chang, H.-H. et al. A new tricarbazole phosphine oxide bipolar host for efficient single-layer blue PhOLED. Org. Electron. 12, 2025-2032 (2011).

5. Yin, Y., Wen, X., Yu, J., Zhang, L. \& Xie, W. Influence of Thickness on Performance of Blue Single-Layer Organic Light-Emitting Device. IEEE Photo. Tech. Lett. 25, 2205-2208 (2013).

6. Yun, C. et al. Influence of phosphorescent dopants in organic light-emitting diodes with an organic homojunction. Appl. Phys. Lett. 101, 243303-263306 (2012).

7. Cai, C. et al. High-efficiency red, green and blue phosphorescent homojunction organic light-emitting diodes based on bipolar host materials. Org. Electron. 12, 843-850 (2011).

8. Wang, Q. et al. High-Performance, Phosphorescent, Top-Emitting Organic LightEmitting Diodes with p-i-n Homojunctions. Adv. Funct. Mater. 21, 1681-1686 (2011).

9. Walzer, K., Maenning, B., Pfeifer, M. \& Leo, K. Highly Efficient Organic Devices Based on Electrically Doped Transport Layers. Chem. Rev. 107, 1233-1271 (2007).

10. Liu, S., Li, B., Zhang, L., Song, H. \& Jiang, H. Enhanced efficiency and reduced rolloff in nondoped phosphorescent organic light-emitting devices with triplet multiple quantum well structures. Appl. Phys. Lett. 97, 083304-083307 (2010).

11. Liu, S., Li, B., Zhang, L. \& Yue, S. Low-voltage, high-efficiency nondoped phosphorescent organic light-emitting devices with double-quantum-well structure. Appl. Phys. Lett. 98, 163301-163304 (2011).

12. Liu, Y. et al. Amidinate-ligated iridium(III) bis(2-pyridyl)phenyl complex as an excellent phosphorescent material for electroluminescence devices. Chem. Comm. 3699-3701 (2009).

13. Peng, T. et al. A phosphorescent material with high and balanced carrier mobility for efficient OLEDs. Chem. Comm. 47, 3150-3152 (2011).

14. Peng, T. et al. Highly efficient phosphorescent OLEDs with host-independent and concentration-insensitive properties based on a bipolar iridium complex. J. Mater. Chem. C 1, 2920-2926 (2013).

15. Liu, Z. W. et al. Red Phosphorescent Iridium Complex Containing CarbazoleFunctionalized $\beta$-Diketonate for Highly Efficient Nondoped Organic LightEmitting Diodes. Adv. Funct. Mater. 16, 1441-1448 (2006).

16. Song, Y.-H. et al. Bright and Efficient, Non-doped, Phosphorescent Organic RedLight-Emitting Diodes. Adv. Funct. Mater. 14, 1221-1226 (2004).

17. Xia, D. et al. Self-host blue-emitting iridium dendrimer with carbazole dendrons: nondoped phosphorescent organic light-emitting diodes. Angew. Chem. Int. Ed. 53, 1048-1053 (2013).

18. Xu, X. et al. Efficient nondoped white organic light-emitting diodes based on electromers. Appl. Phys. Lett. 89, 123503-123506 (2006).

19. Tong, Q.-X. et al. High-efficiency nondoped white organic light-emitting devices. Appl. Phys. Lett. 91, 023503-023506 (2007).
20. Zhao, Y., Chen, J. \& Ma, D. Ultrathin nondoped emissive layers for efficient and simple monochrome and white organic light-emitting diodes. ACS Appl. Mater. Interfaces. 5, 965-971 (2013).

21. Zhao, Y., Chen, J. \& Ma, D. Realization of high efficiency orange and white organic light emitting diodes by introducing an ultra-thin undoped orange emitting layer. Appl. Phys. Lett. 99, 163303-163306 (2011).

22. Xie, W., Liu, S. \& Zhao, Y. A nondoped-type small molecule white organic lightemitting device. J. Phys. D: Appl. Phys. 36, 1246-1248 (2003).

23. Zhu, J. et al. Lighting object-based nondoped-type white organic light-emitting diode with $\mathrm{N}, \mathrm{N}^{\prime}$-diphenyl-N, $\mathrm{N}^{\prime}$-bis(1-naphthyl)-(1,1'-benzidine)-4,4'-diamine as the chromaticity-tuning layer. Opt. Lett. 32, 3537-3539 (2007).

24. Cao, H. et al. An orange iridium(iii) complex with wide-bandwidth in electroluminescence for fabrication of high-quality white organic light-emitting diodes. J. Mater. Chem. C 1, 7371-7379 (2013).

25. Hsu, F.-M. et al. A Bipolar Host Material Containing Triphenylamine and Diphenylphosphoryl-Substituted Fluorene Units for Highly Efficient Blue Electrophosphorescence. Adv. Funct. Mater. 19, 2834-2843 (2009).

26. Matsusue, N., Suzuki, Y. \& Naito, H. Charge Carrier Transport in Neat Thin Films of Phosphorescent Iridium Complexes. Jpn. J. Appl. Phys. 44, 3691-3694 (2005).

27. Lee, Y.-T., Chiang, C.-L. \& Chen, C.-T. Solid-state highly fluorescent diphenylaminospirobifluorenylfumaronitrile red emitters for non-doped organic light-emitting diodes. Chem. Comm. 2, 217-219 (2008).

28. Wu, W.-C., Yeh, H.-C., Chan, L.-H. \& Chen, C.-T. Red Organic Light-Emitting Diodes with a Non-doping Amorphous Red Emitter. Adv. Mater. 14, 1072-1075 (2002).

29. Yeh, H.-C., Chan, L.-H., Wu, W.-C. \& Chen, C.-T. Non-doped red organic lightemitting diodes. J. Mater. Chem. 14, 1293-1298 (2004).

30. Chi, C.-C. et al. Achieving high-efficiency non-doped blue organic light-emitting diodes: charge-balance control of bipolar blue fluorescent materials with reduced hole-mobility. J. Mater. Chem. 19, 5561-5571 (2009).

31. Tsuboi, T., Murayama, H., Yeh, S.-J., Wu, M.-F. \& Chen, C.-T. Photoluminescence characteristics of blue phosphorescent Ir3+-compounds FIrpic and FIrN4 doped in mCP and SimCP. Opt. Mater. 31, 366-371 (2008).

32. Dedeian, K., Shi, J., Shepherd, N., Forsythe, E. \& Morton, D. C. Photophysical and Electrochemical Properties of Heteroleptic Tris-Cyclometalated Iridium(III) Complexes. Inorg. Chem. 44, 4445-4447 (2005).

33. Holmes, R. J. et al. Efficient, deep-blue organic electrophosphorescence by guest charge trapping. Appl. Phys. Lett. 83, 3818 (2003).

34. Mulder, C. L., Celebi, K., Milaninia, K. M. \& Baldo, M. A. Saturated and efficient blue phosphorescent organic light emitting devices with Lambertian angular emission. Appl. Phys. Lett. 90, 211109 (2007).

\section{Acknowledgments}

This work was supported by the National Natural Science Foundation of China (Grant Nos. 61474054, 61475060, 61177026, 61306054, 61306055), New Century Excellent Talents in University (No. 100446) and the Ministry of Science and Technology of China (Grant No. 2010CB327701).

\section{Author contributions}

Y.M.Y. designed and conducted most of the experiments, analyzed the data and prepared the manuscript. J.Y. performed blue and orange OLEDs fabrication and characterization. H.T.C. and H.Z.S. contributed to the synthesis of (pbi) $)_{2} \operatorname{Ir}(\mathrm{biq})$. L.T.Z. helped with the white OLED fabrication experiments. W.F.X. initiated the study, designed all the experiments, analyzed the data and prepared the manuscript. All authors discussed the results and commented on the manuscript.

\section{Additional information}

Competing financial interests: The authors declare no competing financial interests.

How to cite this article: Yin, Y. et al. Efficient non-doped phosphorescent orange, blue and white organic light-emitting devices. Sci. Rep. 4, 6754; DOI:10.1038/srep06754 (2014).

This work is licensed under a Creative Commons Attribution-NonCommercialNoDerivs 4.0 International License. The images or other third party material in this article are included in the article's Creative Commons license, unless indicated otherwise in the credit line; if the material is not included under the Creative Commons license, users will need to obtain permission from the license holder in order to reproduce the material. To view a copy of this license, visit http:// creativecommons.org/licenses/by-nc-nd/4.0/ 